\title{
Altruistic behavior: mapping responses in the brain
}

This article was published in the following Dove Press journal:

Neuroscience and Neuroeconomics

4 November 2016

Number of times this article has been viewed

\author{
Megan M Filkowski' \\ R Nick Cochran' \\ Brian W Haas ${ }^{1,2}$ \\ 'Department of Psychology, \\ 2Interdisciplinary Neuroscience \\ Graduate Program, University of \\ Georgia, Athens, GA, USA
}

Correspondence: Brian W Haas Department of Psychology, University of Georgia, Athens, GA 30602, USA Email bhaas@uga.edu

\begin{abstract}
Altruism is an important social construct related to human relationships and the way many interpersonal and economic decisions are made. Recent progress in social neuroscience research shows that altruism is associated with a specific pattern of brain activity. The tendency to engage in altruistic behaviors is associated with greater activity within limbic regions such as the nucleus accumbens and anterior cingulate cortex in addition to cortical regions such as the medial prefrontal cortex and temporoparietal junction. Here, we review existing theoretical models of altruism as well as recent empirical neuroimaging research demonstrating how altruism is processed within the brain. This review not only highlights the progress in neuroscience research on altruism but also shows that there exist several open questions that remain unexplored.
\end{abstract}

Keywords: altruism, fMRI, social neuroscience

\section{Introduction}

Altruism is a social and interpersonal construct related to various types of prosocial behavior. While its definition varies depending on the discipline, altruism is often defined as an action that is done with the intention of helping another. In essence, biologists and evolutionary scientists often focus on the benefit of a particular behavior while psychologists are interested in understanding the motivation behind the behavior. From a biological or evolutionary perspective, altruism is a behavior that decreases the fitness or genetic contribution of one individual while increasing the fitness of another. ${ }^{1}$ In psychological research, altruism is conceptualized as a motivational state that a person possesses with the goal of increasing the welfare of another person. ${ }^{2}$ Altruism is, therefore, opposed by egoism, which is the motivation to increase one's own welfare. Understanding why humans engage in prosocial behaviors such as altruism when it is often contrary to our own self-interest and occasionally our well-being has been a topic of increasing interest, both behaviorally and within the brain.

Altruism and related constructs such as cooperation and reciprocity are mostly viewed as uniquely human traits; ${ }^{3}$ however, some aspects of these constructs have been reported in other species. For example, monkeys will refuse food when they learn that by taking the food, a shock will be delivered to another monkey. ${ }^{4}$ Dolphins have been reported to help other dolphins who have been caught in nets, ${ }^{5}$ and elephants will give support to other elephants who are too weak to stand or who are emotionally distressed. ${ }^{6}$ In humans, there is evidence that infants exhibit altruistic behavior beginning at a young age. For example, infants as young as 14-18 months of age assist others in obtaining out-of-reach objects and help to open cabinets for others. ${ }^{7}$ Infants 
engage in these behaviors without reward or encouragement from an adult and expectedly without knowledge of concepts such as reciprocation and reputation. Warneken and Tomasello ${ }^{7}$ suggest that altruistic behaviors observed in children may serve to maintain and foster future altruistic behaviors throughout development and into adulthood.

Previous behavioral research suggests that humans willingly interact with strangers in ways that are beneficial to others, even when it is not in their own best interest. ${ }^{8}$ Additionally, humans have been reported to continue to engage in altruistic behaviors even in situations when there will be no future interaction. ${ }^{9}$ Fehr and Fischbacher ${ }^{3}$ suggest that if two strangers are allowed to engage in repeated anonymous monetary exchanges in the laboratory, there exists a high probability that altruistic behavior will spontaneously emerge. Therefore, these findings propose that there appears to be a natural tendency for humans to exhibit altruistic behaviors.

While prosocial acts benefit others, research suggests that individuals engaged in altruistic behaviors also benefit. Several studies report physical and psychological benefits associated with altruistic behavior. For example, volunteerism is positively correlated with self-reported happiness, health, and well-being. ${ }^{10}$ Hunter and Linn ${ }^{11}$ demonstrated that when compared to those who did not volunteer, older adults who volunteered regularly showed greater satisfaction in life and exhibited reduced rates of depression and anxiety. Volunteerism and helping behavior are also associated with physical health and longevity. ${ }^{12}$ In a study investigating the effects of volunteerism on physical health, Moen et $\mathrm{al}^{13}$ showed that mothers who belonged to a volunteer group were less likely to experience a major illness. In a study of adults over 55 years of age, individuals were $63 \%$ less likely to die if they had volunteered for multiple groups in a given time point. Even after controlling for health status prior to the study, volunteering was associated with a significant reduction (44\%) in mortality. ${ }^{14}$ Engaging in acts of kindness has also been associated with increased well-being. These findings indicate that being aware of the kindness of others and of ones own acts of kindness is related to increased self-reported levels of well-being. ${ }^{15} \mathrm{~A}$ study by Otake et $\mathrm{al}^{15}$ asked participants to count the number of acts of kindness they performed for one week. The experimental data were compared with a control condition that did not partake in the "counting kindness" task. Results indicated that counting acts of kindness significantly increased self-reported levels of happiness. ${ }^{15}$ Together, these studies suggest that altruistic behaviors not only benefit others but also have profound positive effects on the current and future physical and psychological well- being of the person performing the behavior. In this article, we review theoretical models of human altruism and recent neuroimaging research demonstrating how altruism is processed within the brain. First, we will review concepts of altruism followed by the ways in which altruism has been measured behaviorally. Finally, we review empirical neuroimaging research, which has directly investigated the neural correlates of altruistic behavior.

\section{Concepts of altruistic behavior}

Altruism is often associated with other concepts such as altruistic punishment, reward, reciprocity, and cooperation. Altruistic punishment (a powerful social tool that can persuade social defectors to behave prosocially) plays a central role in maintaining cooperation. ${ }^{16,17}$ Altruistic punishment results in the punishment of an individual for violating a social norm, often by a third party or outside observer who is not directly affected by the violation. In a study completed by Fehr et al, ${ }^{8}$ participants played a public goods game (PGG) with two conditions. One condition allowed another person to punish those who did not play fairly while the other condition did not allow punishment. Specifically, at the end of each round, each participant could pay to allocate a punishment, ranging from 1 to 10 points, to the member being punished. Each point would cost the participant 1 monetary unit but would cost the punished participant 3 monetary units. The researchers found that in situations where altruistic punishment is a possibility, cooperation is more likely, but when altruistic punishment is not allowed, the rate of cooperation is greatly reduced.

Reciprocity, which is similar to altruism in that the action may be harmful to the self and beneficial to another, involves the expectation that the other person will act similarly in a subsequent interaction. Reciprocal altruism is more likely to take place in small groups of isolated people, which allows repeated interactions. A person who is a strong reciprocator obeys social norms of a group and therefore tends to punish partners or group members who violate social norms. Strong reciprocators have the predisposition to cooperate even where there is no apparent benefit to doing so. There is evidence that during in-group situations, rewarding and punishing others based on social norms results in cooperation. ${ }^{8}$ These effects of punishing can translate to future encounters where previously punished individuals increase cooperation with new partners. ${ }^{8}$

Cooperation and altruism are often studied together or considered equivalent constructs. Cooperation takes place when two or more people work together to achieve a common goal. ${ }^{18}$ Cooperation involves working toward a common goal where both parties are invested, whereas altruistic behaviors 
are often one sided with no overt positive outcome for the party engaging in altruistic behavior. A type of cooperation known as conditional cooperation occurs when an individual is initially willing to take a risk and cooperate in a particular situation because they believe that others will act similarly in a subsequent interaction. This behavior may change if the partner or group members do not also cooperate. ${ }^{19}$ This is different from cooperation because in traditional cooperation both parties involved are equally at risk, while in conditional cooperation, one person is willing to increase their risk in hopes that it will pay off later. Cooperation is therefore similar to reciprocal altruism because having knowledge about the intentions of others is an important motivator for cooperative behavior. $^{8}$

\section{Measuring altruism Self-report measures}

In psychological research, altruism is demonstrated through prosocial behaviors, which can be measured via self-report scales that specifically measure altruistic behavior or through personality measures (Table 1). The Altruistic Personality $\mathrm{Scale}^{20}$ measures altruistic tendencies by gauging the frequency that a person engages in prosocial behaviors. Altruistic behavior in the workplace, which involves actions by an organization's employees who are meant to help others but are not formally rewarded,$^{21}$ has been studied using the Citizenship Behavior Scale and the Helping Behavior Scale..$^{22}$ The Organizational Citizenship Behavior Scale measures five facets of workplace altruism, and the Helping Behavior Scale was designed to measure global altruism and helping behavior in work place. ${ }^{16}$ Another way to measure altruism is through the Big Five Model of Personality. Specifically, the altruism facet within the global trait of Agreeableness on the NEO Personality Inventory is often used to assess altruistic tendencies. ${ }^{23}$ Additionally, economic and neuroeconomic studies tend to utilize behavioral measures of altruism because they are readily available, easy to use, and have been shown to be reliable for measuring altruism.

\section{Behavioral measures of altruism}

Behavioral paradigms have also been used to measure altruistic behaviors in people. These tasks often require participants to make decisions regarding the likelihood of positive or negative outcomes that will affect themselves and/or their partner within the task scenario. Since altruism is a positive trait and individuals may exhibit bias with selfreport measures, the behavioral paradigms have the added benefit of measuring actual behavior within a social situation. There are several different behavioral paradigms that have been employed in altruism research including the ultimatum game (UG), dictator game (DG), the trust game (TG), the prisoner's dilemma (PD), and the PGG (Table 2).

\section{The ultimatum game}

In the UG, two individuals (Persons A and B) are partnered together. Person A is given a pre-determined amount of money and instructed to divide the money between him/ herself and Person B, the partner, in any way they deem fit. Person A then offers the amount to the partner. Person A may only make one offer. Person B must then either accept or reject the offer. If Person B accepts the offer, both partners receive the money as allocated by Person A. If Person $B$ rejects the offer, neither individual receives any money. Logically, any offer should be accepted, since without an acceptance neither individual profits. However, if the split is perceived as unfair, Person B can punish their partner by rejecting the unfair offer. The UG is an example of altruistic punishment being used to penalize Person A for engaging in

Table I Self-report measures to measure altruism

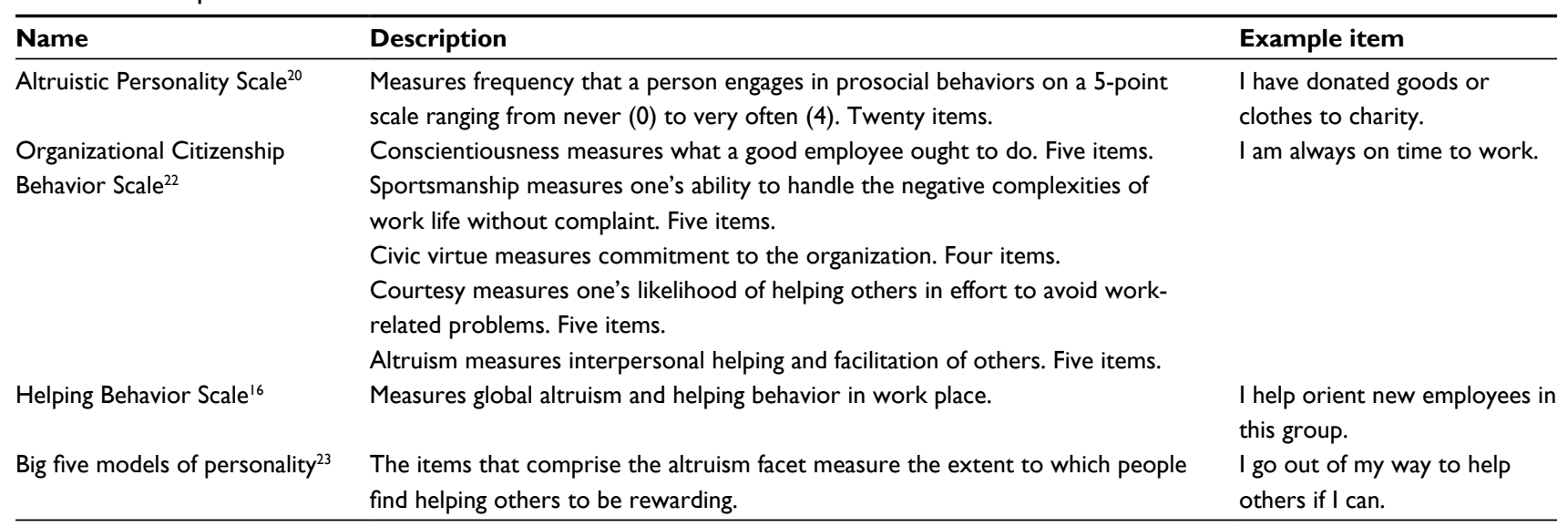


Table 2 Behavioral measures

\begin{tabular}{|c|c|c|}
\hline Name & Description & How the game measures altruism \\
\hline $\begin{array}{l}\text { Ultimatum } \\
\text { game (UG) }\end{array}$ & $\begin{array}{l}\text { Person A is given a pre-determined amount of money and } \\
\text { instructed to divide the money between him/herself and Person B. } \\
\text { Person B must then either accept or reject the offer. If Person B } \\
\text { accepts the offer, both partners receive the money as allocated by } \\
\text { Person A. If Person B rejects the offer, neither individual receives } \\
\text { any money. }\end{array}$ & $\begin{array}{l}\text { The UG is an example of altruistic punishment being used to } \\
\text { penalize Person A for engaging in unfair behavior. }\end{array}$ \\
\hline $\begin{array}{l}\text { Dictator } \\
\text { game }\end{array}$ & $\begin{array}{l}\text { Person A ("the dictator") is instructed to divide a sum of money } \\
\text { into two parts for himself and Person B ("the recipient"). The } \\
\text { recipient has no opportunity to influence the outcome of the } \\
\text { game and simply receives the sum of money the dictator allocates. }\end{array}$ & $\begin{array}{l}\text { Per homo economicus, individuals who choose to share the } \\
\text { endowment with the recipient in the game are engaging in } \\
\text { altruistic behavior. }\end{array}$ \\
\hline $\begin{array}{l}\text { Trust game } \\
\text { (TG) }\end{array}$ & $\begin{array}{l}\text { Person A allocates a sum of money to Person B. Once allocated, } \\
\text { researchers multiply the allocated portion by a specified amount. } \\
\text { Then, Person B must decide how much of their allocation should } \\
\text { be returned to Person A. }\end{array}$ & $\begin{array}{l}\text { Altruism in the TG is measured by how Person B splits the } \\
\text { newly allocated funds, since Person A has no input on the funds } \\
\text { once Person B could keep the entire allocation to themselves. } \\
\text { When they split the endowment they are acting altruistically. }\end{array}$ \\
\hline $\begin{array}{l}\text { Public goods } \\
\text { game }\end{array}$ & $\begin{array}{l}\text { Participants are given money in the form of tokens which they } \\
\text { may either keep or donate to the theoretical community coffers. } \\
\text { The tokens that participants donate are then divided equally } \\
\text { among all persons at the end of a round. }\end{array}$ & $\begin{array}{l}\text { The most beneficial outcome for a single person is to donate } \\
\text { nothing, as they will still receive a share of donated tokens at } \\
\text { the end of the round so when they cooperate and donate to the } \\
\text { pot they are acting altruistically. }\end{array}$ \\
\hline
\end{tabular}

unfair behavior. The rejection is likely to influence Person A to make more fair offers in the future if the game is played in an iterative fashion. However, the threat of rejection in single shot versions also places pressure to offer an equitable split. ${ }^{24}$ In the UG, Person A most often decides to split the money equally with the second, when they could take all the money for themselves without repercussions. Interestingly, when Person B is not offered their equal share $(-50 \%)$, they will sometimes reject the offer despite the fact that they will not receive any money. These results go against the rational choice for both players. ${ }^{25}$

\section{The dictator game}

The DG is a modified version of the UG. In the DG, Person A ("the dictator") is instructed to divide a sum of money into two parts for him/herself and Person B ("the recipient"). However, the recipient has no opportunity to influence the outcome of the game and simply receives the sum of money the dictator allocates. This game has been used to test the concept of Homo economicus, or the economic man, which describes the portrayal of humans in many economic models. ${ }^{26}$ The economic man is entirely self-interested and rational, so logic follows that, in the $\mathrm{DG}$, the economic man would take the entire endowment, leaving nothing for the recipient. Per Homo economicus, individuals who choose to share the endowment with the recipient in the game are engaging in altruistic behavior. Unless played iteratively with alternating roles of the dictator, the recipient has no course of retribution. Thus, the motivation behind prosocial behavior in the DG may be to conform to societal norms or an effort to build a positive reputation. ${ }^{27}$ Much like in the UG, during the DG the results do not always match the predicted findings. For example, in most iterations of the DG the dictator often gives the other person an amount of money (as opposed to no money at all). Additionally, the dictator tends to share about one-fifth of the allocated money to his/her partner. Giving any money at all shows altruistic tendency as they could keep it all to themselves without any repercussion. ${ }^{27}$

\section{The trust game}

The TG is a behavioral task designed to measure the tendency to trust others. The TG requires Person A to allocate a sum of money to Person B. Once allocated, the sum of money is multiplied by a pre-specified value. Then, Person B must decide how much of his/her allocation should be returned to Person A. Thus, Person A may allocate more money to Person B with the hope of receiving that amount or more when the partner reallocates the multiplied share of the endowment. Here, Person A's allocation is interpreted as an act of trust in Person B. If Person A allocates more money to the partner, he/she is trusting that Person B will return the favor. In this game, altruism is measured by how Person B splits the newly allocated funds, since Person A has no input on the funds once Person B has decided how much to share. However, if the game is played repeatedly, Person A may change the initial allocation to Person B based on the amount received in previous rounds. Alternatively, if roles are switched with each new round, additional factors may be introduced..$^{28}$ In 
actual sessions of the TG, Person A often entrusts $>50 \%$ of their original endowment to Person $\mathrm{B} .{ }^{29}$ In addition, the amount of returned endowment from Person B changes when experimenters manipulate the social information available to the participants. However, despite what social information is known, the returned endowment is often greater than the amount they received from Person A. ${ }^{29}$ Person B often gives back more than they received, acting contrary to the Homo economicus model, in an altruistic manner.

\section{The public goods game}

Finally, the PGG is designed to study altruism in groups rather than pairs. In the PGG, participants are given money in the form of tokens, which they may either keep or donate to the theoretical community coffers. The tokens that participants donate are then divided equally among all persons. Logically, the most beneficial outcome for a single person is to donate nothing, as they will still receive a share of donated tokens at the end of the round. In one shot versions of the game, $40-60 \%$ cooperation has been recorded. ${ }^{9}$ However, this figure degrades very quickly in iterative versions, since people's strategies may change in order to punish a participant who does not donate. Ultimately, this leads to smaller rewards for the group as a whole. ${ }^{30}$ If participants act in their own self-interest, they should not put any tokens into the pot and yet still reap the rewards of the group. However, research has found that most people contribute to the pot, though the amount contributed often varies based on the multiplicative factor the researchers use. ${ }^{31}$ When a person does not contribute to the pot they are known as a "free rider", and when they do contribute, they can be said to be acting altruistically. These "free riders" often incur altruistic punishment from others in subsequent rounds in attempts to force cooperation.

\section{Altruism in the brain \\ Brain regions associated with altruism}

Key structures that may be involved during altruistic decision making and subsequent altruistic behavior include regions within the mentalizing network such as the medial prefrontal cortex (mPFC) and temporoparietal junction (TPJ), reward regions including the ventral tegmental area (VTA), striatum, specifically the nucleus accumbens $(\mathrm{NaCC})$, and anterior cingulate cortex (ACC), and regions of the emotional salience network including the dorsolateral prefrontal cortex (DLPFC), insula, and amygdala (Figure 1).

Altruistic behavior may engage brain regions such as the VTA, striatum, $\mathrm{NaCC}$, a part of the striatum, and ACC that is

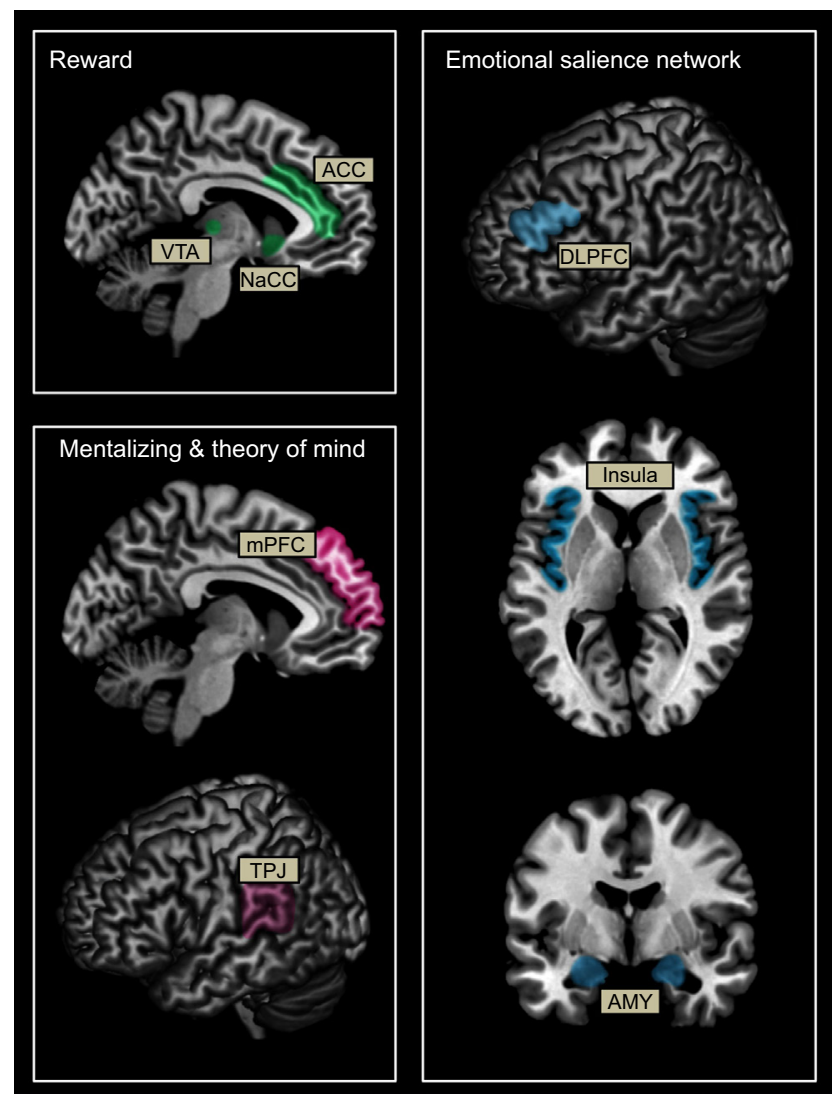

Figure I Schematic representation of brain networks associated with reward (green), mentalizing and theory of mind (pink), and emotional salience (blue) thought to be involved in altruistic behavior.

Abbreviations: AMY, amygdala; ACC, anterior cingulate cortex; DLPFC, dorsolateral prefrontal cortex; mPFC, medial prefrontal cortex; $\mathrm{NaCC}$, nucleus accumbens; TPJ, temporoparietal junction; VTA, ventral tegmental area.

associated with reward processing. The VTA, striatum, and $\mathrm{NaCC}$ comprise the core reward processing regions associated with pleasure. ${ }^{32,33}$ The striatum is also associated with reputation processing ${ }^{34}$ and is activated when recognizing and evaluating potential rewards as well as learning from those encounters. ${ }^{35}$ The ACC, a multimodal region of frontal cortex, is associated with pain and conflict monitoring ${ }^{36}$ and emotional perception. ${ }^{37,38}$ In addition, the ACC is also involved in anticipation of potential rewards $\mathrm{s}^{39,40}$ and therefore may play an important role in the analysis of potential benefits of altruistic behavior. Anticipation of potential rewards, whether from external sources (eg, a better reputation) or internal sources (eg, the "warm glow" effect), may facilitate altruistic decisions.

Brain regions within the mentalizing/theory of mind (ToM) network may be involved in altruism behavior. The $\mathrm{mPFC}$ is involved in reputation processing, ${ }^{34}$ mentalizing, and in self-referential processing, specifically, determining boundaries between the self and others. ${ }^{41}$ The mPFC is also associated with emotion processing, ${ }^{42,43}$ and ToM. ${ }^{44,45}$ The 
combination of evaluation of others versus the self, ToM, and reputation processing makes the $\mathrm{mPFC}$ an important candidate in altruistic behavior and decision making. Also part of the mentalizing network, the TPJ is involved in ToM ${ }^{46-50}$ and perspective taking. ${ }^{51,52}$ Together, activation in these regions is likely if individuals are actively engaged in thinking about not only the emotions and feelings of others but also about their own thoughts, feelings, and desired outcomes.

Finally, regions involved in cognitive control and emotion processing including the DLPFC, amygdala, and insula may also be associated with altruistic behavior. The DLPFC is involved in the effortful regulation of attention and categorization of emotional stimuli. ${ }^{38,53}$ In addition, the DLPFC has reciprocal connections to other important emotion processing regions of the emotional salience network such as the amygdala, insula, ACC, and hippocampus. ${ }^{54-57}$ The amygdala plays an important role in attention, specifically, the amygdala functions to alert the brain to important stimuli and is particularly sensitive to emotional stimuli. ${ }^{58}$ The insula is involved in processing of emotional stimuli; particularly negative stimuli, in addition to interoceptive states. ${ }^{59,60}$ In terms of altruism, these regions may facilitate orientation of attention to emotionally provocative situations and stimuli. Regions such as the insula may be associated with negative emotions in response to either the distress of a partner or when thinking about the consequences of selfish choices. In addition, these regions may be involved during the integration of information related to the cost-benefit analysis performed when weighing the decision to make costly acts for others.

In the following section, we review current neuroimaging research investigating the neural correlates of altruism. Research investigating prosocial behavior often utilizes various behavioral paradigms to measure prosocial behavior other than aforementioned tasks commonly used in behavioral research. Therefore, a literature search was conducted to find all neuroimaging studies investigating altruism in healthy human adults via PubMed from January 1, 1997, to November 1, 2015. Studies were included if they directly measured altruistic behavior, generally, which included paradigms such as charitable/altruistic giving, altruistic helping, and altruistic punishment using functional magnetic resonance imaging (fMRI).

\section{Altruistic giving and the brain}

Altruistic giving involves the allocation of money to either a partner or a group such as a charity. The most common paradigm employed by studies of altruistic giving is the DG, ${ }^{61,62}$ which involves no overt external pressures to give such as punishment by a partner who is allocated an unfair amount. Other altruistic giving studies investigate decisions to donate money to charities.

In a study investigating decisions to donate to charitable causes, participants chose to give money in order to donate to causes or withhold donations to unfavorable causes. ${ }^{63}$ The decision to lose money in order to donate to or oppose a cause was associated with neural reactivity in the anterior prefrontal cortex including the mPFC, bilateral ACC, and frontopolar cortex. Activation in these regions was also associated with self-reported charitable engagement. Donating in general (whether at a personal loss or not) was associated with VTAstriatum reactivity, a region that was also reactive during pure monetary gain. SgACC activity was reported specifically for costly donations compared with pure monetary gain. Results of this study suggest that, when making costly altruistic decisions, a combination of regions within the reward network is involved in donations of any sort in addition to activation in regions involved in self-other understanding such as the $\mathrm{mPFC}$ and regions involved in emotional responses such as the SgACC. This suggests that both reward and concern for others may be motivators for altruistic behaviors.

Harbaugh et al reported increased activation in rewardrelated regions of the brain in response to several types of monetary exchanges. ${ }^{64}$ This study evaluated neural responses when participants either were given the choice to donate to charity or were forced to give to two charities in a dictator style game. Results indicated that regions including the bilateral caudate, right $\mathrm{NaCC}$, and bilateral insula were active when either the participant or the charity received money. However, participants who exhibited more activation in response to obtaining money for themselves were less likely to donate to charity, whereas participants who exhibited more activation when the charity received money were more likely to donate to charity and had higher self-reported satisfaction when giving.

Hare et $\mathrm{al}^{65}$ also investigated charitable donations, but chose to explore the effect of the subjective value of the charity in deciding how much to donate. In this study, participants were endowed $\$ 100$ for participating in the study and told that they could keep any money they chose not to donate. Participants rated the deservingness of each charity as well as how close they felt to the charity prior to the donation task. While in the scanner, participants were presented with a name of a charity and asked how much money they would like to donate. Importantly, at the end of the task, one charitable donation decision was chosen at random, matched by the researchers, and donated to the charity. Therefore, 
participants could engage in each decision separately as the money was not spread out among decisions. Ventromedial PFC (vmPFC) activity was associated with the subjective value of donations. Functional connectivity analysis showed that regions in the posterior superior temporal sulcus (pSTS) and anterior insula were functionally connected to the vmPFC. The authors suggest that the vmPFC may be involved in evaluating the value of making decisions to donate to charities, which may be affected by the pSTS and anterior insula, regions involved in social cognition. ${ }^{65}$

Zaki and Mitchell ${ }^{66}$ suggested that altruistic and equitable allocation may be its own reward and investigated the possibility that equitable offers might activate reward regions. In this iterative DG study, participants were instructed to choose between two monetary offers: one for the self and one for a partner. The offers varied so that in some cases, the individual could receive significantly more than the partner or the partner could receive significantly more than the individual. Controlling for the amount of money participants stood to gain, orbitofrontal cortex (OFC) reactivity was associated with equitable decisions compared with inequitable decisions. Even when participants stood to gain the most by selfish choices, equitable decisions were accompanied by increased activity in this reward-related region. The authors suggest that activity in this region may be associated with the evaluation of subjective value of prosocial choices. ${ }^{66}$ In addition, unfair/selfish decisions were associated with increased anterior insula activity, and individuals who exhibited the strongest anterior insula activity in response to unfair decisions also exhibited fewer unfair decisions. This suggests that unfair or selfish choices may result in negative emotional states in the individual that may affect subsequent behavior.

Waytz et $\mathrm{al}^{67}$ investigated the role of ToM and empathic concern on subsequent altruistic behavior during the DG. Participants first completed a ToM task during which they were instructed to make social judgments about preferences and personality traits of a confederate. Subjects then engaged in an iterative version of the DG to measure altruistic giving behavior. Furthermore, as an additional measure of altruism, subjects were also asked to donate time to the confederate by completing problem-solving questions. Subjects were instructed that they could answer as few or as many as they wished. Increased dorsal $\mathrm{mPFC}$ activity predicted subsequent allocation of more money and time to the partner. Individuals who exhibited more dorsal $\mathrm{mPFC}$ activation during the ToM task also spent more time answering the problem-solving questions and allocated more money to their partner. In a separate analysis, dorsal mPFC activity during the decision to allocate money to the partner was associated with increased monetary allocation. This finding provides further support for the importance of emotional responses to others' mental states when making altruistic decisions.

Together these studies suggest that regions associated with reward processing including the $\mathrm{NaCC}$ and $\mathrm{OFC}$ as well as areas involved in emotion and self-other processing such as the mPFC and SgACC are activated when engaging in altruistic giving. Furthermore, the insula activation, which is associated with interoceptive processing, may play a role in modulating the behavior of the individual by inducing negative emotional states in response to selfish/unfair behaviors toward others.

\section{Altruistic helping, punishment, and the brain}

Helping others who have been wronged (altruistic helping) and punishing the individual who violates social norms (altruistic punishment) are both considered altruistic behaviors. In the helping condition, individuals attempt to help the person who has been wronged, whereas in the punishment condition, the violator is punished in an effort to pressure the individual into conforming to social norms (eg, equitable allocation of money). Altruistic helping and altruistic punishment can be investigated from partners involved directly in exchanges or by third parties who view participants of DGs.

A study of third-party altruistic helping and punishment found that both behaviors resulted in increased activation of the striatum. ${ }^{68}$ In their study, Hu et al ${ }^{68}$ presented participants with unfair monetary allocations made during the DG. Participants were then given the option to either help the wronged subject or punish the dictator. At a cost of 1 monetary unit (MU), 3 MUs were either given to the wronged person or taken away from the person playing the dictator role. In addition to increased activation in the bilateral striatum, a functional connectivity analysis found increased connectivity between the right lateral prefrontal cortex and the bilateral striatum when choosing to help, while punishment was associated with increased connectivity with the vmPFC and the left lateral prefrontal cortex. ${ }^{68}$ In addition, self-reported empathic concern was positively correlated with decisions to help. Individuals with higher empathic concern exhibited increased fronto-parietal activity when deciding to help. Results from this study suggest that while both altruistic helping and punishment may activate reward regions, helping and punishment may each have distinct networks involved. In addition, individual differences in empathic concern are related to decisions to help. 
Another way to measure altruistic helping is to evaluate how much an individual is willing to spend to reduce the discomfort of another. When making the decision to keep money for oneself or spend money to prevent a confederate from receiving an electric shock, FeldmanHall et al ${ }^{69}$ found that altruistic decisions were associated with activation of the DLPFC. Watching the consequences of altruistic decisions was associated with increased reactivity of reward-related regions including the VTA, $\mathrm{NaCC}$, and caudate in addition to the SgACC. Importantly, neural reactivity was not related to subjects' perception of being watched or reputation management. Furthermore, altruistic responses were related to the self-reported empathic concern subscale of the Interpersonal Reactivity Inventory (IRI) rather than the personal distress subscale. Results from this study support the idea that individuals who make altruistic decisions exhibit an increased DLPFC response that is associated with empathic concern for others rather than to reduce personal distress. Furthermore, viewing the consequences of altruistic decisions was associated with increased activation of several reward-related regions, which may help reinforce altruistic behaviors.

Evaluation of the person in need has also been shown to affect costly helping behavior. Specifically, evaluation of the individual's associations such as team membership or ethnic group, whether negative or positive, affects an individual's willingness to help. In a study of ingroup versus outgroup helping, Hein et $\mathrm{al}^{70}$ reported two competing neural responses that predicted costly helping behavior. Viewing an ingroup member in pain was associated with increased anterior insula reactivity whereas viewing an outgroup member in pain was associated with $\mathrm{NaCC}$ activation. ${ }^{70}$ Individuals who exhibited greater anterior insula activity and higher self-reported empathic concern were more likely to endure physical pain to reduce the pain of the ingroup member. In contrast, increased $\mathrm{NaCC}$ activation and a higher self-reported negative evaluation of the other individual were associated with refusal to help. The authors suggest that both group membership and evaluation of the individual work together to predict costly helping. Individuals who exhibit increased reactivity in regions such as the insula, which are associated with empathy are more likely to help, but with outgroup members; a negative evaluation is associated with reward-related regions of the $\mathrm{NaCC}$ suggesting that individuals may experience pleasure in another's pain. ${ }^{70}$

Unlike the studies mentioned earlier, Marsh et $\mathrm{al}^{71}$ investigated a group of extreme altruists, anonymous kidney donors. The authors theorized that altruism and caring behavior lie on a continuum with extreme altruists on one side and psychopaths, who typically lack empathy and care for others, on the other side. ${ }^{71}$ The study investigated responses to emotional faces, specifically fearful expresses, which are strong elicitors of compassion and altruism. ${ }^{72}$ Given that previous research has reported that psychopaths exhibit reduced amygdala volume and function to fearful faces, the authors hypothesized that extreme altruists would exhibit the opposite result with increased amygdala volume and function in response to fearful faces. Participants judged the sex of faces expressing fear, anger, happy, or neutral expressions of various intensities. Compared with healthy controls, extreme altruists exhibited increased right amygdala and right DLPFC reactivity to fearful faces relative to neutral faces. Extreme altruists also had significantly larger right amygdala volume in relation to healthy controls. Behaviorally, extreme altruists recognized fear better than healthy controls. Together the results of this study suggest concern for others' emotions and response to others' emotions, specifically for potential threat, and increased right amygdala volume is associated with altruistic behavior. Extreme altruists appear to be particularly perceptive of the emotional cues of fearful facial expression in others, which may result in increased activation of regions related to empathy that may in turn affect altruistic behaviors.

Altruism has also been associated with neural response to agency, the ability to make independent choices and actions. Tankersley et $\mathrm{al}^{73}$ conducted an experiment during which participants either watched or participated in a reaction time game while fMRI data were collected. Post-scan, subjects completed a self-report measure of altruism, and in a follow-up experiment, subjects also completed measures of personality, impulsiveness, and empathy. Results indicated that the right posterior STS (pSTS) exhibited increased activation during the watch condition when compared with the play condition, and pSTS reactivity was associated with selfreported altruism but not to other measures (eg, personality or empathy). The authors suggest that these results indicate that the ability to perceive the actions of others as self-generated and goal-oriented may be the underlying mechanism for mentalizing, ToM, and altruism. ${ }^{73}$

Taken together, it appears that both reward regions, regions involved in ToM and mentalizing, and regions associated with emotion processing are involved while making altruistic decisions. Across studies, several regions including the $\mathrm{mPFC} / \mathrm{vmPFC}, \mathrm{NaCC} / \mathrm{VTA}$, STS, and SgACC were associated with altruistic behavior (Figure 2). These findings suggest that engaging in altruistic behavior may indeed be its own reward, and by identifying others' emotional and mental states through ToM, individuals are more likely to 


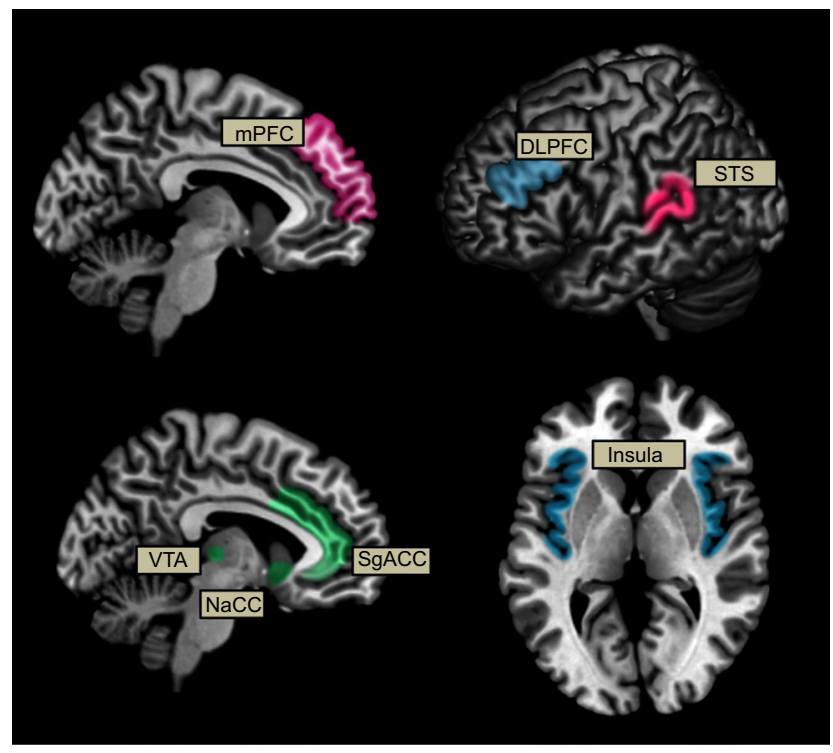

Figure 2 Schematic representation of neural activation associated with altruistic behavior during fMRI.

Notes: Color represents brain networks associated with reward (green), mentalizing and theory of mind (pink), and emotional salience (blue). Note, blue regions (DLPFC/insula) also appeared task dependent.

Abbreviations: DLPFC, dorsolateral prefrontal cortex; fMRI, functional magnetic resonance imaging; mPFC, medial prefrontal cortex; $\mathrm{NaCC}$, nucleus accumbens; SgACC, subgenual anterior cingulate cortex; STS, superior temporal sulcus; VTA, ventral tegmental area.

engage in such behaviors. Other regions such as the DLPFC and insula, which are associated with the emotional salience network, may be task dependent (blue regions in Figure 2). The insula may play a role in inducing negative emotional states in the individual when engaging in unfair or selfish actions during the DG and the DLPFC may be associated with increased attention toward reducing pain in others, at a monetary cost to the individual. In addition, individual differences in empathy may also play an important role and are associated with differential neural activity and subsequent behaviors.

\section{Conclusion}

Research on altruism serves to advance the way people maintain healthy interpersonal relationships and serves to advance the understanding of economic decision making. Although considerable progress in behavioral and neuroimaging research clearly shows that under a wide range of scenarios humans tend to behave altruistically, we also know that there exist scenarios where people behave selfishly. It is currently unknown, however, how specific state and trait variables affect the way people make altruistic versus selfish decisions. This research is important to facilitate the way groups and organizations are structured in order to encourage altruism.
This review also highlights the role of a network of brain regions associated with the tendency to make altruistic decisions. An open question for future research is how this evidence can translate to the benefit of actual people. For example, if one learns that their brain is well suited to be altruistic, would this serve as an additional motivation to actually behave altruistically? Also, how would knowledge of the opposite "predisposition" affect altruistic behavior? If one learns that they possess a predisposition toward selfish decision making, are there ways that this information could be used to motivate a person toward making relatively altruistic types of decisions.

Finally, it is currently unknown how several of the experimental paradigms reviewed in this article translate to "real-world" decision making. This is especially true for paradigms used while fMRI data are being collected. Future research is required to characterize the ecological validity of altruistic behavioral research on the way people actually live their lives.

\section{Disclosure}

This research did not receive any specific grant from funding agencies in the public, commercial, or not-for-profit sectors. The authors report no conflicts of interest in this work.

\section{References}

1. De Waal FB. Putting the altruism back into altruism: the evolution of empathy. Annu Rev Psychol. 2008;59:279-300.

2. Wilson DS. On the relationship between evolutionary and psychological definitions of altruism and selfishness. Biol Philos. 1992;7(1): 61-68.

3. Fehr E, Fischbacher U. The nature of human altruism. Nature. 2003;425(6960):785-791.

4. Masserman JH, Wechkin S, Terris W. "Altruistic" behavior in rhesus monkeys. Am J Psychiatry. 1964;121:584-585.

5. Connor RC, Norris KS. Are dolphins reciprocal altruists? Am Nat. 1982:358-374.

6. Payne K. Silent Thunder: In the Presence of Elephants. New York: Simon and Schuster; 1998.

7. Warneken F, Tomasello M. The roots of human altruism. Br J Psychol. 2009; 100(pt 3):455-471.

8. Fehr E, Fischbacher U, Gächter S. Strong reciprocity, human cooperation, and the enforcement of social norms. Hum Nat. 2002;13(1):1-25.

9. Fehr E, Rockenbach B. Human altruism: economic, neural, and evolutionary perspectives. Curr Opin Neurobiol. 2004;14(6):784-790.

10. Musick MA, Wilson J. Volunteering and depression: the role of psychological and social resources in different age groups. Soc Sci Med. 2003;56(2):259-269.

11. Hunter KI, Linn MW. Psychosocial differences between elderly volunteers and non-volunteers. Int J Aging Hum Dev. 1980;12(3):205-213.

12. Post SG. Altruism, happiness, and health: it's good to be good. Int $J$ Behav Med. 2005;12(2):66-77.

13. Moen P, Dempster-McClain D, Williams RM Jr. Successful aging: a life-course perspective on women's multiple roles and health. Am J Sociol. 1992;97(6):1612-1638.

14. Oman D, Thoresen CE, McMahon K. Volunteerism and mortality among the community-dwelling elderly. J Health Psychol. 1999;4(3):301-316. 
15. Otake K, Shimai S, Tanaka-Matsumi J, Otsui K, Fredrickson BL. Happy people become happier through kindness: a counting kindnesses intervention. J Happiness Stud. 2006;7(3):361-375.

16. Van Dyne L, LePine JA. Helping and voice extra-role behaviors: evidence of construct and predictive validity. Acad Manag J. 1998;41(1):108-119.

17. Fehr E, Gächter S. Altruistic punishment in humans. Nature. 2002;415(6868):137-140.

18. Tuomela R. What is cooperation? Erkenntnis. 1993;38(1):87-101.

19. Kocher MG, Cherry T, Kroll S, Netzer RJ, Sutter M. Conditional cooperation on three continents. Econ Lett. 2008;101(3):175-178.

20. Rushton JP, Chrisjohn RD, Fekken GC. The altruistic personality and the self-report altruism scale. Pers Individ Dif. 1981;2(4):293-302.

21. Organ DW. Organizational Citizenship Behavior: The Good Soldier Syndrome. Lexington, MA: Lexington Books, DC Heath and Com; 1988.

22. Podsakoff PM, MacKenzie SB, Moorman RH, Fetter R. Transformational leader behaviors and their effects on followers' trust in leader, satisfaction, and organizational citizenship behaviors. Leadership $Q$. 1990;1(2):107-142.

23. Costa PT, McCrae RR, Dye DA. Facet scales for agreeableness and conscientiousness: a revision of the NEO personality inventory. Pers Individ Dif. 1991;12(9):887-898.

24. Güth W, Schmittberger R, Schwarze B. An experimental analysis of ultimatum bargaining. J Econ Behav Organ. 1982;3(4):367-388.

25. Kahneman D, Knetsch JL, Thaler RH. Fairness and the assumptions of economics. J Bus. 1986:S285-S300.

26. Persky J. Retrospectives: the ethology of homo economicus. J Econ Perspect. 1995;9(2):221-231.

27. Forsythe R, Horowitz JL, Savin NE, Sefton M. Fairness in simple bargaining experiments. Games Econ Behav. 1994;6(3):347-369.

28. Burks SV, Carpenter JP, Verhoogen E. Playing both roles in the trust game. J Econ Behav Organ. 2003;51(2):195-216.

29. Berg J, Dickhaut J, McCabe K. Trust, reciprocity, and social history. Games Econ Behav. 1995;10(1):122-142.

30. Andreoni J. Why free ride? strategies and learning in public goods experiments. J Public Econ. 1988;37(3):291-304.

31. Gunnthorsdottir A, Houser D, McCabe K. Disposition, history and contributions in public goods experiments. J Econ Behav Organ. 2007;62(2):304-315.

32. Liu X, Hairston J, Schrier M, Fan J. Common and distinct networks underlying reward valence and processing stages: a metaanalysis of functional neuroimaging studies. Neurosci Biobehav Rev. 2011;35(5):1219-1236.

33. Sescousse G, Caldú X, Segura B, Dreher J-C. Processing of primary and secondary rewards: a quantitative meta-analysis and review of human functional neuroimaging studies. Neurosci Biobehav Rev. 2013;37(4):681-696.

34. Izuma K, Saito DN, Sadato N. The roles of the medial prefrontal cortex and striatum in reputation processing. Soc Neurosci. 2010;5(2):133-147.

35. Bhanji JP, Delgado MR. The social brain and reward: social information processing in the human striatum. Wiley Interdiscip Rev Cogn Sci. 2014;5(1):61-73.

36. Vogt BA. Pain and emotion interactions in subregions of the cingulate gyrus. Nat Rev Neurosci. 2005;6(7):533-544.

37. Devinsky O, Morrell MJ, Vogt BA. Contributions of anterior cingulate cortex to behaviour. Brain. 1995;118(1):279-306.

38. Phillips ML, Drevets WC, Rauch SL, Lane R. Neurobiology of emotion perception I: the neural basis of normal emotion perception. Biol Psychiatry. 2003;54(5):504-514.

39. Rogers RD, Ramnani N, Mackay C, et al. Distinct portions of anterior cingulate cortex and medial prefrontal cortex are activated by reward processing in separable phases of decision-making cognition. Biol Psychiatry. 2004;55(6):594-602.

40. Rushworth MF, Noonan MP, Boorman, Walton ME, Behrens TE. Frontal cortex and reward-guided learning and decision-making. Neuron. 2011;70(6):1054-1069.
41. Amodio DM, Frith CD. Meeting of minds: the medial frontal cortex and social cognition. Nat Rev Neurosci. 2006;7(4):268-277.

42. Etkin A, Egner T, Kalisch R. Emotional processing in anterior cingulate and medial prefrontal cortex. Trends Cogn Sci. 2011;15(2):85-93.

43. Sabatinelli D, Bradley MM, Lang PJ, Costa VD, Versace F. Pleasure rather than salience activates human nucleus accumbens and medial prefrontal cortex. J Neurophysiol. 2007;98(3):1374-1379.

44. Mitchell JP, Macrae CN, Banaji MR. Dissociable medial prefrontal contributions to judgments of similar and dissimilar others. Neuron. 2006;50(4):655-663.

45. Mitchell JP, Neil Macrae C, Banaji MR. Forming impressions of people versus inanimate objects: social-cognitive processing in the medial prefrontal cortex. Neuroimage. 2005;26(1):251-257.

46. Apperly IA, Samson D, Chiavarino C, Humphreys GW. Frontal and temporo-parietal lobe contributions to theory of mind: neuropsychological evidence from a false-belief task with reduced language and executive demands. J Cogn Neurosci. 2004;16(10):1773-1784.

47. Delgado MR, Frank RH, Phelps EA. Perceptions of moral character modulate the neural systems of reward during the trust game. Nat Neurosci. 2005;8(11):1611-1618.

48. Fletcher PC, Happe F, Frith U, et al. Other minds in the brain: a functional imaging study of "theory of mind" in story comprehension. Cognition. 1995;57(2):109-128.

49. Rilling JK, Sanfey AG, Aronson JA, Nystrom LE, Cohen JD. The neural correlates of theory of mind within interpersonal interactions. Neuroimage. 2004;22(4):1694-1703.

50. van Veluw SJ, Chance SA. Differentiating between self and others: an ALE meta-analysis of fMRI studies of self-recognition and theory of mind. Brain Imaging Behav. 2014;8(1):24-38.

51. Van Overwalle F, Baetens K. Understanding others' actions and goals by mirror and mentalizing systems: a meta-analysis. Neuroimage. 2009;48(3):564-584.

52. Frith CD, Frith U. The neural basis of mentalizing. Neuron. 2006; 50(4):531-534.

53. Mitchell DG, Greening SG. Conscious perception of emotional stimuli brain mechanisms. Neuroscientist. 2012;18(4):386-398.

54. Craig A. Interoception: the sense of the physiological condition of the body. Curr Opin Neurobiol. 2003;13(4):500-505.

55. Cauda F, D’Agata F, Sacco K, Duca S, Geminiani G, Vercelli A. Functional connectivity of the insula in the resting brain. Neuroimage. 2011;55(1):8-23.

56. Lee KH, Siegle GJ. Common and distinct brain networks underlying explicit emotional evaluation: a meta-analytic study. Soc Cogn Affect Neurosci. 2009:ns001.

57. Menon V, Uddin LQ. Saliency, switching, attention and control: a network model of insula function. Brain Struct Funct. 2010;214(5-6): 655-667.

58. Sander D, Grafman J, Zalla T. The human amygdala: an evolved system for relevance detection. Rev Neurosci. 2003;14(4):303-316.

59. Cauda F, Costa T, Torta DM, et al. Meta-analytic clustering of the insular cortex: characterizing the meta-analytic connectivity of the insula when involved in active tasks. Neuroimage. 2012;62(1):343-355.

60. Duerden EG, Arsalidou M, Lee M, Taylor MJ. Lateralization of affective processing in the insula. Neuroimage. 2013;78:159-175.

61. Bolton GE, Katok E, Zwick R. Dictator game giving: rules of fairness versus acts of kindness. Int J Game Theory. 1998;27(2):269-299.

62. Camerer CF, Fehr E. Measuring Social Norms and Preferences Using Experimental Games: A Guide for Social Scientists. Pasadena, CA: California Institute of Technology; 2002.

63. Moll J, Krueger F, Zahn R, Pardini M, de Oliveira-Souza R, Grafman J. Human fronto-mesolimbic networks guide decisions about charitable donation. Proc Natl Acad Sci U S A. 2006;103(42):15623-15628.

64. Harbaugh WT, Mayr U, Burghart DR. Neural responses to taxation and voluntary giving reveal motives for charitable donations. Science. 2007;316(5831):1622-1625. 
65. Hare TA, Camerer CF, Knoepfle DT, O’Doherty JP, Rangel A. Value computations in ventral medial prefrontal cortex during charitable decision making incorporate input from regions involved in social cognition. J Neurosci. 2010;30(2):583-590.

66. Zaki J, Mitchell JP. Equitable decision making is associated with neural markers of intrinsic value. Proc Natl Acad Sci U S A. 2011;108(49): 19761-19766.

67. Waytz A, Zaki J, Mitchell JP. Response of dorsomedial prefrontal cortex predicts altruistic behavior. J Neurosci. 2012;32(22):7646.

68. Hu Y, Strang S, Weber B. Helping or punishing strangers: neural correlates of altruistic decisions as third-party and of its relation to empathic concern. Front Behav Neurosci. 2015;9:24.
69. FeldmanHall O, Dalgleish T, Evans D, Mobbs D. Empathic concern drives costly altruism. Neuroimage. 2015;105:347-356.

70. Hein G, Silani G, Preuschoff K, Batson CD, Singer T. Neural responses to ingroup and outgroup members' suffering predict individual differences in costly helping. Neuron. 2010;68(1):149-160.

71. Marsh AA, Stoycos SA, Brethel-Haurwitz KM, Robinson P, VanMeter JW, Cardinale EM. Neural and cognitive characteristics of extraordinary altruists. Proc Natl Acad Sci U S A. 2014;111(42):15036-15041.

72. Marsh AA, Kozak MN, Ambady N. Accurate identification of fear facial expressions predicts prosocial behavior. Emotion. 2007;7(2):239.

73. Tankersley D, Stowe CJ, Huettel SA. Altruism is associated with an increased neural response to agency. Nat Neurosci. 2007;10(2):150-152.
Neuroscience and Neuroeconomics

\section{Publish your work in this journal}

Neuroscience and Neuroeconomics is an international, peer-reviewed, open access journal focusing on the identification of brain structures and measurement of neural activity related to behavior, behavioral predictions, and decision making in health and disease. The manuscript

\section{Dovepress}

management system is completely online and includes a very quick and fair peer-review system. Visit http://www.dovepress.com/testimonials. php to read real quotes from published authors. 